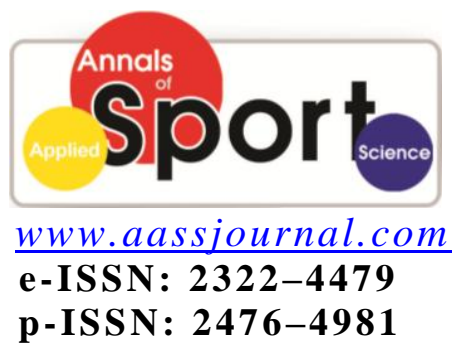

Driginal Article

Received: $19 / 06 / 2015$

Accepted: 30/09/2015

\title{
Developing and Validating a New Wireless Wearable Device for Balance Measurement in Sport and Clinical Setting
}

\section{Mohammad Maleki*, Mehran Faqihsolimany, Behzad Mortezazadeh}

- Department of Physical Education and Sport Sciences, Faculty of Humanities and Social Sciences, University of Kurdistan, Sanandaj, Iran.

\begin{abstract}
One of the new clinical techniques to assess the lower body parameters is the wearable ultrasonic sensors. The device which can measure the static and dynamic balance abilities in sport and clinical setting by the traveled signals of ultrasonic transmitter and receiver between two feet was developed and validated. The new device consisted of a pressure gauge and a digital centimeter indicator and examined the tests in two balanced states of Stork and Y dynamic. First, 210 participants were selected based on convenience sampling. Then, using the new ultrasonic balance device, all samples took each test conducted by the Stork and Y dynamic tests for3 times. The results showed high reliability between the data of static and dynamic balances obtained from the ultrasonic device and through the methods of Stork and Y (the SEBT modified version) $(\mathrm{r}=0.90 ; \mathrm{r}=0.92)$. The inter-rater reliabilities of the three-time conduction of the stork and $\mathrm{Y}$ dynamic tests were found to be very high $(\mathrm{ICC}=0.92 ; \mathrm{ICC}=0.91)$. The ultrasonic balance device was both valid and reliable in measuring the Stork and Y dynamic balance tests. The new device could solve that defects associated with traditional stork and Y dynamic tests.
\end{abstract}

Key Words: Static Balance, Dynamic Balance, Reliability.

Corresponding Author:

Mohammad Maleki

E-mail: mo.maleki@uok.ac.ir 


\section{INTRODUCTION}

Balance is a key component in daily activity and sport performance $(1,2)$. It also plays a decisive role in an athlete's sport performance. A matter of fact, maintaining the proper posture (balance) allows an athlete to fully focus on the required movement task (3). This position requires a complex conflict between the musculoskeletal and nervous systems together with an interaction between static (ability to maintain the center of gravity at the surface) and dynamic balance aspects (active motion of the center of pressure during standing, walking or any other activities) (4). Posture control is a complex coordination between sensory and biomechanical information and muscular activities against external forces, and the loss of any of these factors can increase postural sway and reduce the ability to maintain control over a part or the whole body during movement (5). Then, muscle weakness, loss of proprioception, and reduction of the range of motion are among the factors which affect human postural stability (6).

The primary purposes of clinical balance assessments are to identify whether or not a balance problem exists and also to determine the underlying cause of this problem. The determination of the existence of a balance problem is of great help in predicting the risk of falls and to determine the effectiveness of intervention. Quantitative and norm-referenced tools used to assess postural control in the clinic should include measures which are reflective of both the functional capabilities and quality of postural strategies, sensitive and selective for postural control abnormalities, reliable and valid, easy to use and inexpensive (7). However, the results obtained are subjective, show ceiling effects and scoring errors, and are usually not responsive enough to measure progress or deterioration in a subject's ability to balance (8).
The most prevalent approach is to use balance task functional-based tests. The advantage of these tests is their ability to be used in different situations with low cost, low complexity, an in short time (9). The Stork balance test (10) has been used to measure static balance and may be a useful test for clinical evaluation of a subject's ability to stabilize intrapelvic motion (11). In the Stork test, subjects are asked to stand on a flat surface on one foot and place the other foot on the inner side of the relying foot's knee while their hands are located next to their bodies. Then, the time required for an individual to maintain his/her position for the maximum possible duration is recorded by a stopwatch in seconds (10 to $50 \mathrm{sec}$.). If the relying foot of the subject spins or moves or the other leg is removed from the knee of the relying foot or his/her hands are open and generally in case of any movement by the subject, the stopwatch will be stopped by the experimenter (12).

In literature, two related tests have been used to assess the performance during dynamic single-leg balance tasks, they are: the Star Excursion Balance Test (SEBT) and the Y Balance Test (YBT). The SEBT was originally described as a series of single-leg squats on the stance limb with the contra lateral limb reaching a line in one of eight directions. In an effort to reduce redundancy and improve efficiency, the SEBT was modified from the eight original directions to the three anterior, posteromedial, and posterolateral reach directions $(13,14)$. In two investigations, a comparison of the differences between SEBT and YBT $(15,16)$ tests were found for each distance achieved and kinematics. This led the authors to conclude that the two tests may involve different motor strategies as a result of the differences in instrumentation, scoring mode and protocol specifics. The $\mathrm{Y}$ balance test comprises a network with 3 lines in different directions and an angle of 120 degrees 
determined by using glue strips, tape measure, and a conveyer on the ground. The test is carried out in a way that a person stands on one foot in the core of the network and moves the other foot in 3 directions for three times. After each attempt and change of direction, the subject returns to its initial standing position on one foot. Errors in this test occur when too much pressure is exerted with the finger on the ground, when falling, and moving the relying foot (17).

Having had a good reliability and validity (18), the researchers believe that in evaluating the ability to balance on one and two legs with common means of observation and description, such as the stork and $\mathrm{Y}$ balance tests, there is a possibility of errors by the observer due to errors that cannot be seen visually; therefore, the results may be associated with biases (10). The main sources of these errors can be the test duration, poor grading, the use of manual timer to record events, handy ruler, and subject's surface area $(18,19)$. The disadvantage of these methods is that they give subjective measurements, particularly concerning accuracy and precision, which have a negative effect on the diagnosis, follow-up and treatment of the pathologies. On the other hand, the traditional scales used to measure the postural balance in clinical conditions are semi-subjective, carried out by specialists who observe the quality and ability of a person's standing on one leg. Training balance and evaluating of postural control requires appropriate tracking and feedback of performance. Then, in clinical situations, researchers and experimenters are required to have an instrument to measure the balance with the highest objectivity, in the shortest possible time, and at the lowest cost. To solve this problem, the progress in new technologies has given rise to devices and techniques which allow an objective evaluation of balance parameters, resulting in more efficient measurement and providing specialists with reliable information on participant's ability of balance (20).

Recently, wearable sensors were developed for the measurement of balance control in clinical tests of balance and mobility (21). These sensors, with wireless data transfer, have the potential to overcome the major drawbacks of cost, size and limited location of computerized testing, as well as enabling the objective measurement of postural sway and movements during task performance. Wearable sensor technology can accurately measure the postural control $(22,23)$ and may provide a new avenue for motion feedback during balance tests (24). Also, the incorporation of wearable sensors into balance training has been repeatedly suggested in review articles $(25,26)$. One of the new clinical techniques to measure balance, gait and pathology parameters is the use of ultrasonic sender and receivers. Ultrasonic sensors have been used to measure short step and stride length and the distance between feet $(27,28)$. With the knowledge of the speed at which sound travels through air, ultrasonic sensors measure the time needed to send and receive the wave produced, as it is reflected on an object. With the knowledge of the time it takes the signal to travel and come back, and the speed, it is possible to obtain the distance between the two points (20). Since the ultrasonic sensors have been used for the measurement of lower limb rehabilitation (29-31), considering the importance of accuracy and speed in measurement of the balance abilities, the current research tries to present a newly-designed smart balance measurement device to which whether these sensors are beneficial and practical to develop and measure the static and dynamic postural balance. Then, the questions Does ultrasonic sensors precisely provide the data on static and dynamic balance positions like other technologies, including pressure and force sensors, inertial sensors, goniometers (20) etc.? Can the new tool, a composite of 
functional and wearable tests, fix the defects of mentioned functional balance tests and minimizes the probability of human errors in measurement situations? Will be answered, Also, the reliability and validity of the device will be determined.

\section{MATERIALS AND METHODS}

Participants. For this study, 210 participants (105 male and 105 female) were selected based on convenience sampling method. After filling out the consent form, participants commenced the experiments. They were all right-handed and right-footed, with no history of professional sports or damage to the lower parts of their bodies.

Features of the New Device. The StaticDynamic Ultrasonic Balance (SDUB) device has pressure gauges under the foot and sides of the waist to force a fixed amount of pressure. Therefore, if the pressure is too much or too little, it will be considered as an error. To measure body deviation angle relative to the $\mathrm{x}$ and $\mathrm{y}$ axis, the two-axis angle sensors (zct260j model) with a range of -60 to +60 degrees were installed on a transmitter board. To measure the distance between strides, theSfr05 ultrasonic distance meter with a maximum measureable distance of $4 \mathrm{~m}$ and measurement accuracy of $0.1 \mathrm{~cm}$ were used. Sending and receiving information between the sender and receiver circuits were performed with $9600 \mathrm{bit} / \mathrm{second}$ speed of information transition.

A digital centimeter indicator shows the exact distance $(\mathrm{cm})$ of foot movement in the $\mathrm{Y}$ test by two TTL ultrasonic micro switches. Using a handheld device which has been designed in 2 rows of 6 characters, the type of test can be selected. On a LED screen, the duration and type of test and the number of errors is displayed wirelessly.

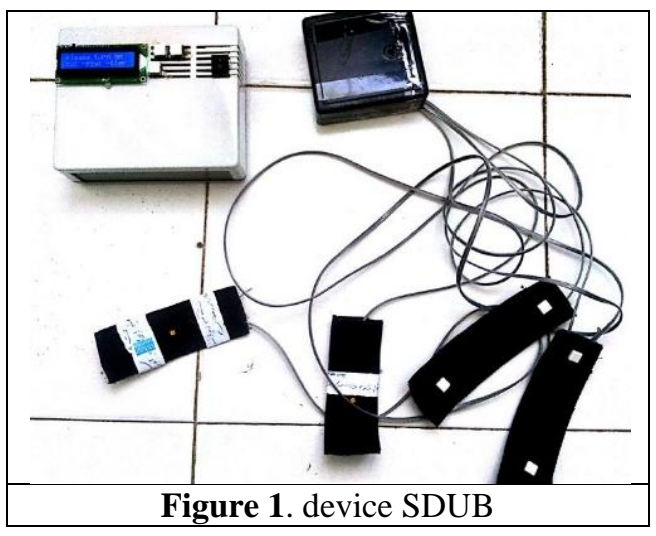

Method of Measurement. Before the tests, the subjects ran and carried out stretching exercises for $10 \mathrm{~min}$ to warm up. One of the common locations for placing the sensors is the trunk $(32,33)$. Hence, the SDUB device was put on their chest during the tests to determine its validity. For each tests of static (Stork test) and dynamic balances (Y test), the subjects performed 6 tries (3 of them was done through the traditional balance measurement method and 3 through the new SDUB device) and the number of errors and the time of first error in the Stork test and the error distance $(\mathrm{cm})$ in the $\mathrm{Y}$ test were recorded. In the Stork test, subjects were asked to stand on a flat surface on one foot and place the other foot on the inner side of the relying foot's knee, while their hands were located next to their bodies. Shortly following this, the time required for an individual to maintain position was recorded by a stopwatch in seconds. If the relying foot of the subject span or moved or the other leg was removed from the knee of the relying foot or his/her hands were open and generally in case of any movement by the subject, the stopwatch was stopped by the experimenter. This process was carried out automatically in the new SDUB device. In the dynamic balance test of $\mathrm{Y}$, the subjects were asked to stand at the center of a circle and lift one foot off the ground and move it 
to the farthest point possible on the 3 predetermined lines. Then, by using the traditional and SDUB methods, the maximum errorless distance was recorded for each participant. In the traditional administration of the $\mathrm{Y}$ test, the experimenter looks at the individual and visually detects the errors; however, in the new SDUB device these shortcomings and ambiguities have been removed and just by clicking the start button, the device automatically detects and records all errors (Figures 2 and 3).
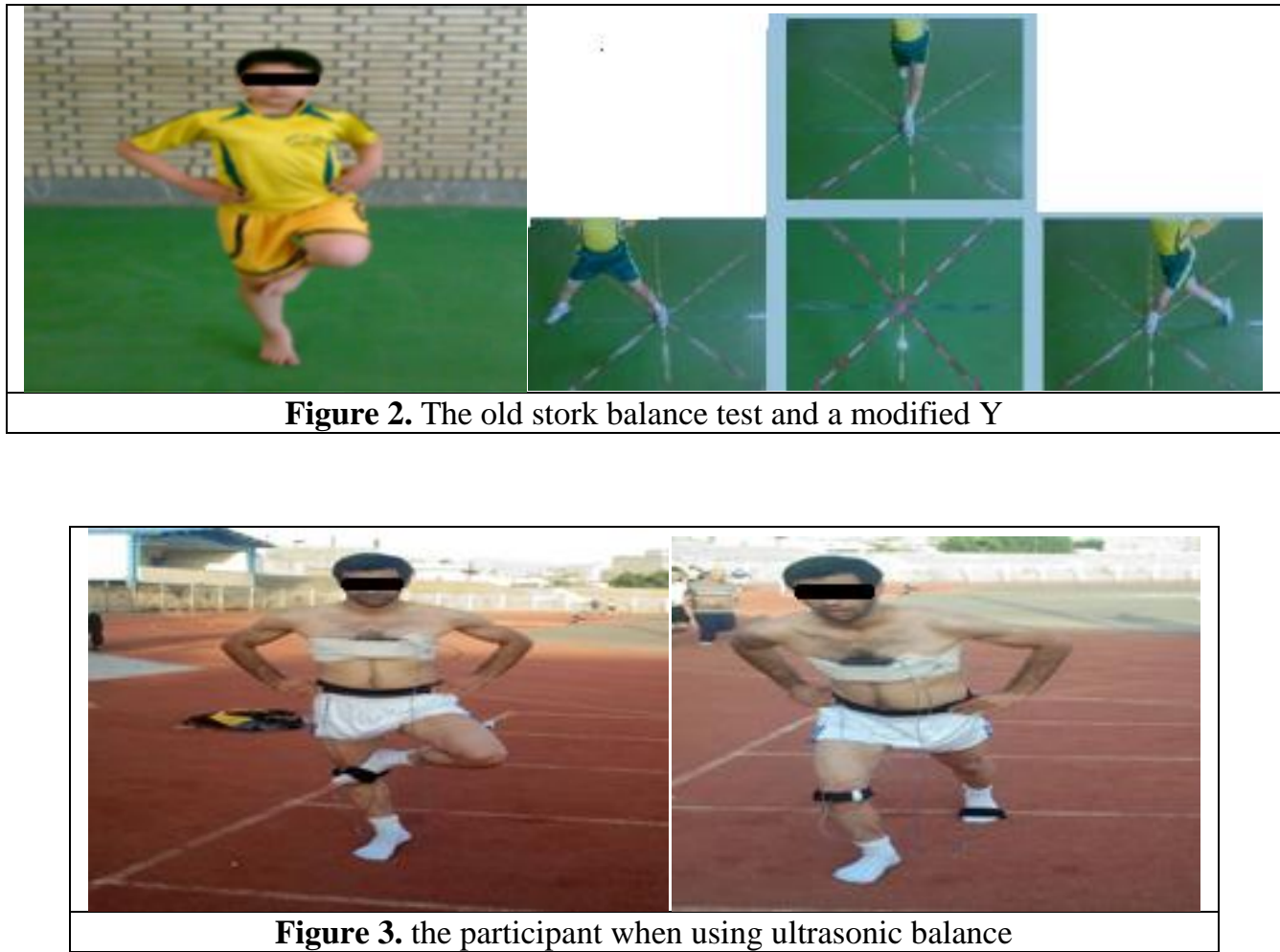

Statistical Analysis. To examine the normality of the data, the KolmogorovSmirnov test and to determine the validity of the SDUB device (to analyze the relationship between the results obtained from the new device and the traditional administration of the Stork and $\mathrm{Y}$ tests), the Spearman correlation analysis were used. The validity of the device was also determined by the inter-rater coefficient (ICC) (34). All of these statistical analyses were done using SPSS (version 18) and at the significance level of 0.05 $(\mathrm{p}<0.05)$.

\section{RESULTS}

\section{The static balance test findings}

Table 1 shows the validity of the static balance by two applied methods. As can be seen, there existed a significant relationship between the values of static balance $(\mathrm{r}=0.92)$. In addition, according to this table, the standard error of measurement in the SDUB device was smaller (3.20) than that in the traditional Stork test Execution (5.30). Table 2 shows the mean of the 3 Stork balance test tries and the reliability coefficient between them in the SDUB device. As can be seen, there was a high internal consistency between the three trials $(\mathrm{ICC}=0.92$ ). According to Table3, significant 
relationships and high correlation coefficients

trials using the SDUB device.

were found between the recorded data of 3

Table 1. Balance stork validity between the two measuring device

\begin{tabular}{cccccc}
\hline & Mean \pm SD & The coefficient of variation & SE (Time) & r & P \\
\hline Traditional balancing test stork & $110.11 \pm 6.57$ & 10.57 & 5.3 & \multirow{2}{*}{0.92} & \multirow{2}{*}{$0.001^{* *}$} \\
SDUB & $112.58 \pm 7.21$ & 12.45 & 3.2 & &
\end{tabular}

Table 2. Results of the reliability test in SDUB in 3 tries

\begin{tabular}{cccc}
\hline & The standard error of measurement (Time) & Amplitude & ICC \\
\hline trial 1 & $112.52 \pm 12.33$ & 25.5 & \\
\cline { 1 - 3 } Trial 2 & $109.12 \pm 9.29$ & 26 & 0.92 \\
\cline { 1 - 3 } Trial 3 & $110.25 \pm 10.85$ & 25 & $(0.91-0.93)$ \\
\cline { 1 - 3 } Total trials & $111.58 \pm 11.85$ & 27 & \\
\hline
\end{tabular}

Table 3. Matrix of correlation coefficients (r) between 3 tries to measure the balance of stork with an electronic balance

\begin{tabular}{cccc}
\hline \multicolumn{5}{c}{ Trial } & 1 & Trial & 2 & Trial 3 \\
\hline Trial 1 & - & & \\
\hline Trial 2 & 0.91 & - & \\
\hline Trial 3 & 0.87 & 0.88 & - \\
\hline
\end{tabular}

\section{The dynamic balance test findings}

Table 4 shows the validity of the dynamic balance by two applied methods. As can be seen, there existed a significant relationship between the values of dynamic balance $(\mathrm{r}=0.90)$.According to this table, the standard error of measurement in the SDUB device was smaller (4.30) than that in the traditional Y test Execution (5.70). Table 5 shows the mean of the $3 \mathrm{Y}$ balance test tries and the reliability coefficient between them in the SDUB device. As can be seen, there exited a high internal consistency between the three trials (ICC=0.91).

According to Table 6, significant relationships and high correlation coefficients were found between the recorded data of 3 trials using the SDUB device.

Table 4. Validity of dynamic balance $\mathrm{Y}$ is measured by two methods

\begin{tabular}{cccccc}
\hline The balance Y & Mean \pm SD & $\begin{array}{c}\text { The coefficient of } \\
\text { variation }(\mathrm{CV})\end{array}$ & $\mathrm{SE}($ Time $)$ & $\mathrm{r}$ & $\mathrm{P}$ \\
\hline traditional Y test & $181.19 \pm 11.69$ & 12.66 & 5.7 & 0.9 & 0.002 \\
SDUB & $185.15 \pm 10.65$ & 13.34 & 4.3 & & \\
\hline
\end{tabular}

Table 5. Balance ultrasonic device reliability test results in 3 tries using $\mathrm{Y}$

\begin{tabular}{cccc}
\hline & SE (Time) & Amplitude & ICC \\
\hline trial 1 & $189.52 \pm 11.87$ & 25 & \\
\cline { 1 - 3 } Trial 2 & $186.12 \pm 10.76$ & 24.5 & 0.91 \\
\cline { 1 - 3 } Trial 3 & $184.52 \pm 10.56$ & 24 & $(0.90-0.92)$ \\
\hline Total trials & $185.85 \pm 10.34$ & 26 & \\
\hline
\end{tabular}


Table 6. The matrix of correlation coefficients (r) between 3 tries to measure Y balance with SDUB

\begin{tabular}{cccc}
\hline & Trial 1 & Trial 2 & Trial 3 \\
\hline Trial 1 & - & & \\
\hline Trial 2 & 0.90 & - & \\
\hline Trial 3 & 0.87 & 0.89 & - \\
\hline
\end{tabular}

\section{DISCUSSION}

Given the existence of errors, such as errors hidden from the eyes of the observer, poor grading, and the use of a ruler or a manual timer in the execution of static and dynamic balance tests, the present study aimed to introduce a newly designed ultrasonic system to debug previous balance measurement tools. In the measurement of balance tests of Stork and Y, the Pearson correlation test results showed significant relationships between the recorded data using the SDUB device and the recorded data using the traditional tests. Balance tests, known as the single-leg stance tests, are widely used for the diagnosis and monitoring of patients in research and clinical settings, due to its simplicity, highreliability and low cost (35). However, the main result of this test is greatly enriched if it is supplemented with the devices for precise recording. Based on these results, it can be said that the SDUB device has the ability to measure errors, time, and distance, with accuracy better than the traditional tools.

The average time and distance of the Stork and $Y$ balances measured by the SDUB were, respectively 5 seconds and $4 \mathrm{~cm}$ less than those measured by the traditional tools. These differences can be related to the differences in the measurement process of these two tools. The SDUB device measures the static and dynamic balances and records their patterns through sending signals and signals returning from the different parts of the body, whereas these actions are carried out through the eyes of the experimenter in the traditional methods. Moreover, in a traditional Stork test, the experimenter waits until an error occurs and then stops the stopwatch; but the SDUB device automatically calculates the time when the first error occurs. These situations can be justified by the standard error of measurement in the two methods $(17,36,37)$. The standard error of measurement of the Stork and $\mathrm{Y}$ balance tests in the traditional method were 5.3 and 5.7, respectively whereas they were, respectively 3.2 and 4.3 in the SDUB method, indicating less measurement error in the newly designed device in comparison with the traditional methods. Consequently, the differences between the data recorded by the two measurement tools could be due to the different processes applied in data collection. Our results are consistent with that study of Qi et al. (2014) on extracting the spatialtemporal gait parameters (38), and Maki et al. (2012) study on measurement of stride length (27). They both applied wireless ultrasonic sensors and showed that the ultrasonic sensors possessed high and good reliability for assessing the lower body parameters in sport and clinical standing position.

Apart from validity, reliability is also of great importance. Reliability is an important property of an instrument to ensure its measurement stability and reproducibility. With increased reliability, the measurement error of the instrument decreases. Applying the new technologies used for the single-leg test, including accelerometers (39), inertial (33) and ultrasonic sensors (27, 29-31, 38) have been accompanied with good intra and inter observer reliability. They are valid and sensitive instruments used for precise measurements during postural balance testing. In the present study, due to the high reliability of the static (Stork) and dynamic 
balances (Y) (0.92 and 0.91, respectively), it can be said that when the subjects performed the tests appropriately, the recorded time and distance by the SDUB device demonstrated similar results in different measurements. The high reliability of the SDUB device makes it a secure and authentic device when it is to be used in research studies with a large sample size. It can also be used repeatedly to measure the balance of individuals at different times and with high reliability.

\section{CONCLUSION}

Overcoming the biases accompanied with the experimenter during the static and dynamic balance tests has always been one of the objectives of research in the field of health and sports. Like other wearable wireless systems, the high validity and reliability of the SDUB device, in addition to lower standard error of measurement in comparison with the traditional methods, are indicative of its accuracy in the measurement of the Stork and $\mathrm{Y}$ balances and is a good reproducibility of its test results which is very important in balance tests. Therefore, with regard to high validity and reliability of the device, together with its special advantages over other instruments in the measurement and analysis of balance tests of Stork and Y, researchers in the field of sports and clinical setting are recommended to use this device in their investigations and evaluation of balance tests.

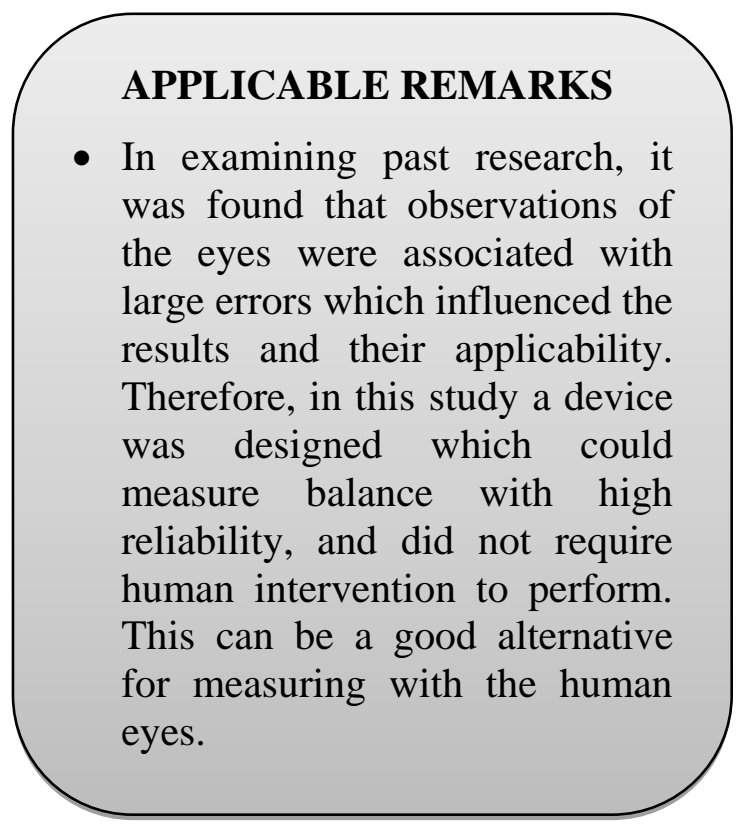

\section{REFFRENCES}

1. Hertel J, Gay MR, Denegar CR. Differences in Postural Control During Single-Leg Stance Among Healthy Individuals With Different Foot Types. Journal of Athletic Training. 2002;37(2):129-32.

2. Woledge RC. Possible effects of fatigue on muscle efficiency. Acta physiologica Scandinavica. 1998;162(3):267-73.

3. Winter DA, Patla AE, Frank JS. Assessment of balance control in humans. Medical progress through technology. 1990;16(1-2):31-51.

4. Berg K. Balance and its measure in the elderly: a review. Physiotherapy Canada. 1989;41(5):240-6.

5. Whitney S, Wrisley D, Furman J. Concurrent validity of the Berg Balance Scale and the Dynamic Gait Index in people with vestibular dysfunction. Physiotherapy research international : the journal for researchers and clinicians in physical therapy. 2003;8(4):178-86.

6. Mackintosh S, Datson N, Fryer C. A balance screening tool for older people: Reliability and validity. International Journal of Therapy \& Rehabilitation. 2006;13(12):558-61.

7. Horak FB. Clinical assessment of balance disorders. Gait \& Posture. 1997;6(1):76-84.

8. Blum L, Korner-Bitensky N. Usefulness of the Berg Balance Scale in stroke rehabilitation: a systematic review. Phys Ther. 2008;88(5):559-66.

9. Farrell MK. Using Functional Assessment and Screening Tools With Frail Older Adults. Topics in Geriatric Rehabilitation. 2004;20(1):14-20.

10. Gladwell V, Head S, Haggar M, Beneke R. Does a program of Pilates improve chronic non-specific low back pain? Journal of sport rehabilitation. 2006;15(4):338-50.

11. Hungerford BA, Gilleard W, Moran M, Emmerson C. Evaluation of the ability of physical therapists to palpate intrapelvic motion with the Stork test on the support side. Phys Ther. 2007;87(7):879-87.

12. Punakallio A. Balance abilities of workers in physically demanding jobs: With special reference to firefighters of different ages. Journal of Sports Science and Medicine. 2005;4(8):1-47. 
13. Herrington L, Hatcher J, Hatcher A, McNicholas M. A comparison of Star Excursion Balance Test reach distances between ACL deficient patients and asymptomatic controls. The Knee. 2009;16(2):149-52.

14. Shaffer SW, Teyhen DS, Lorenson CL, Warren RL, Koreerat CM, Straseske CA, et al. Y-balance test: a reliability study involving multiple raters. Military medicine. 2013;178(11):1264-70.

15. Coughlan GF, Fullam K, Delahunt E, Gissane C, Caulfield BM. A comparison between performance on selected directions of the star excursion balance test and the Y balance test. J Athl Train. 2012;47(4):366-71.

16. Fullam K, Caulfield B, Coughlan GF, Delahunt E. Kinematic analysis of selected reach directions of the Star Excursion Balance Test compared with the Y-Balance Test. J Sport Rehabil. 2014;23(1):27-35.

17. Cobb SC, Tis LL, Johnson BF, Higbie EJ. The effect of forefoot varus on postural stability. The Journal of orthopaedic and sports physical therapy. 2004;34(2):79-85.

18. Langley FA, Mackintosh SF. Functional balance assessment of older community dwelling adults: a systematic review of the literature. Internet Journal of Allied Health Sciences and Practice. 2007;5(4):1-13.

19. Tsai LC, Yu B, Mercer VS, Gross MT. Comparison of different structural foot types for measures of standing postural control. The Journal of orthopaedic and sports physical therapy. 2006;36(12):942-53.

20. Muro-de-la-Herran A, Garcia-Zapirain B, Mendez-Zorrilla A. Gait Analysis Methods: An Overview of Wearable and Non-Wearable Systems, Highlighting Clinical Applications. Sensors (Basel, Switzerland). 2014;14(2):3362-94.

21. Bonato P. Advances in wearable technology and applications in physical medicine and rehabilitation. Journal of NeuroEngineering and Rehabilitation. 2005;2:2-.

22. Najafi B, Bharara M, Talal TK, Armstrong DG. Advances in balance assessment and balance training for diabetes. Diabetes Management. 2012;2(4):293-308.

23. Najafi B, Horn D, Marclay S, Crews RT, Wu S, Wrobel JS. Assessing postural control and postural control strategy in diabetes patients using innovative and wearable technology. Journal of diabetes science and technology. 2010;4(4):780-91.

24. Schwenk M, Grewal GS, Honarvar B, Schwenk S, Mohler J, Khalsa DS, et al. Interactive balance training integrating sensor-based visual feedback of movement performance: a pilot study in older adults. J Neuroeng Rehabil. 2014;11:164.

25. van Diest M, Lamoth CJ, Stegenga J, Verkerke GJ, Postema K. Exergaming for balance training of elderly: state of the art and future developments. J Neuroeng Rehabil. 2013;10:101.

26.Zijlstra A, Mancini M, Chiari L, Zijlstra W. Biofeedback for training balance and mobility tasks in older populations: a systematic review. Journal of NeuroEngineering and Rehabilitation. 2010;7:58-.

27. Maki H, Ogawa H, Yonezawa Y, Hahn AW, Caldwell WM. A new ultrasonic stride length measuring system. Biomedical sciences instrumentation. 2012;48:282-7.

28. Wahab Y, Bakar NA, editors. Gait analysis measurement for sport application based on ultrasonic system. Consumer Electronics (ISCE), 2011 IEEE 15th International Symposium on; 2011 14-17 June 2011.

29. Edgar S, Swyka T, Fulk G, Sazonov ES. Wearable shoe-based device for rehabilitation of stroke patients. Conference proceedings : Annual International Conference of the IEEE Engineering in Medicine and Biology Society IEEE Engineering in Medicine and Biology Society Annual Conference. 2010;2010:3772-5.

30. Neaga F, Moga D, Petreus D, Munteanu M, Stroia N. A Wireless System for Monitoring the Progressive Loading of Lower Limb in Post-Traumatic Rehabilitation. In: Vlad S, Ciupa RV, editors. International Conference on Advancements of Medicine and Health Care through Technology: 29th August - 2nd September 2011, ClujNapoca, Romania. Berlin, Heidelberg: Springer Berlin Heidelberg; 2011. p. 54-9.

31. Wada C, Sugimura Y, Wada F, Hachisuka K, Ienaga T, Kimuro Y, et al., editors. Development of a rehabilitation support system with a shoe-type measurement device for walking. SICE Annual Conference 2010, Proceedings of; 2010 18-21 Aug. 2010.

32. Huisinga JM, St George RJ, Spain R, Overs S, Horak FB. Postural response latencies are related to balance control during standing and walking in patients with multiple sclerosis. Arch Phys Med Rehabil. 2014;95(7):1390-7.

33. Perez-Cruzado D, Gonzalez-Sanchez M, Cuesta-Vargas AI. Parameterization and reliability of single-leg balance test assessed with inertial sensors in stroke survivors: a cross-sectional study. Biomedical engineering online. 2014;13:127.

34. Pincivero D, Lephart S, Henry T. Learning effects and reliability of the Biodex Stability System. J Athl Train. 1995;30:S35.

35. Nott CR, Neptune RR, Kautz SA. Relationships between frontal-plane angular momentum and clinical balance measures during post-stroke hemiparetic walking. Gait Posture. 2014;39(1):129-34.

36. Olmsted LC, Hertel J. Influence of foot type and orthotics on static and dynamic postural control. Journal of Sport Rehabilitation. 2004;13(1):54-66.

37. Riemann BL, Myers JB, Lephart SM. Sensorimotor System Measurement Techniques. Journal of Athletic Training. 2002;37(1):85-98.

38. Qi Y, Soh CB, Gunawan E, Low KS, Thomas R. Estimation of spatial-temporal gait parameters using a low-cost ultrasonic motion analysis system. Sensors (Basel). 2014;14(8):15434-57.

39. Lugade V, Fortune E, Morrow M, Kaufman K. Validity of using tri-axial accelerometers to measure human movement - Part I: Posture and movement detection. Med Eng Phys. 2014;36(2):169-76. 
تازههاى علوم كاربردى ورزش

مقاله اصيل

دوره سوم، شماره جهارم

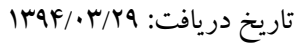

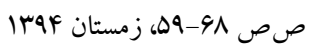

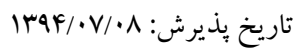

\section{طراحى و روايى سنجى دستخاه بىسيم براى اندازهَيرى تعادل موقعيتهاى ورزشى و بالينى}

\section{'محمد ملكى *، 'مهران فقيهسليمانى، بَبهزاد مر تضىز اده}

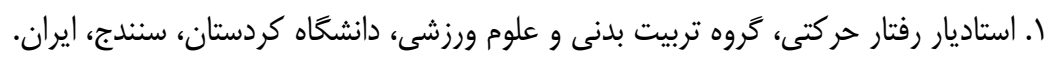

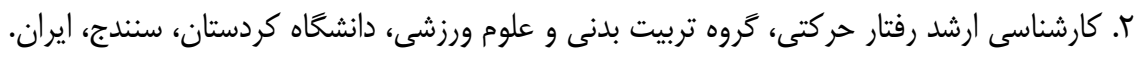

جكيده

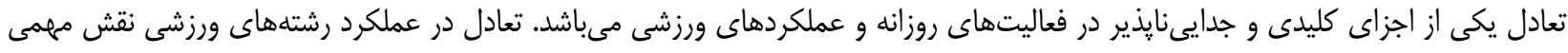

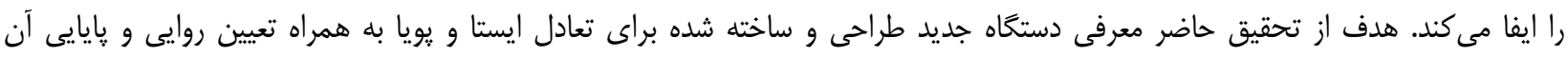

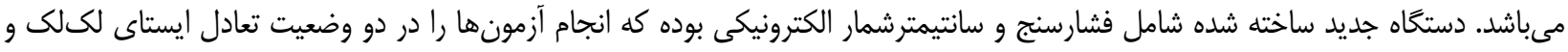

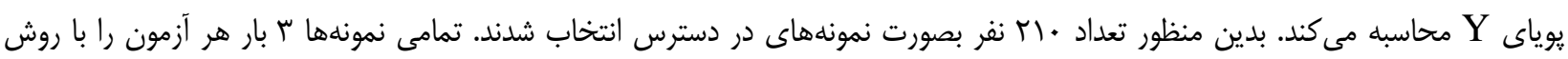

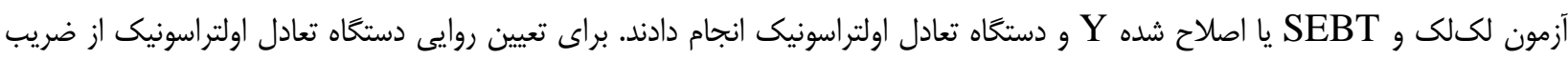

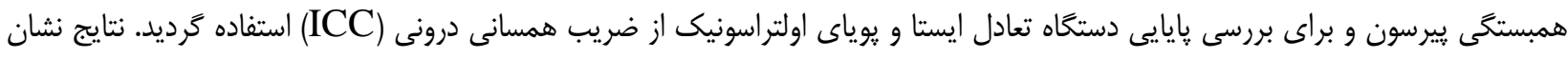

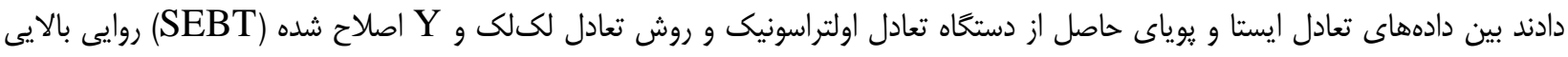

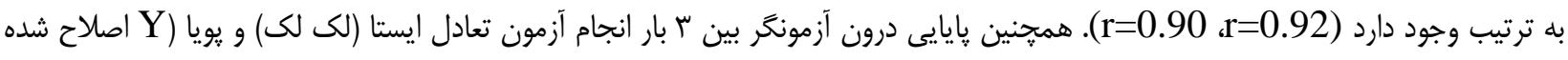

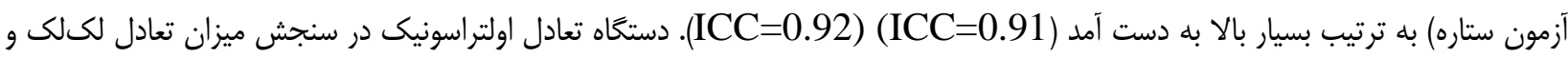

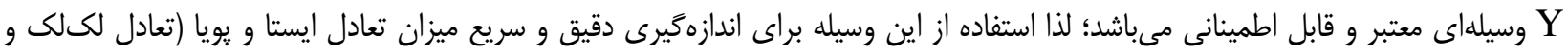
(Y وازَّان كليدى: تعادل ايستا، تعادل يويا، هايايى. 